\title{
FE-CU İKİLİ ALAŞIMLARININ KUTU BORLAMA DAVRANIŞINA BAKIR MİKTARININ ETKİSİ
}

\author{
Sezgin CENGİZ, Yücel GENÇER, Mehmet TARAKÇI, Yunus AZAKLI \\ Gebze Teknik Üniversitesi, Malzeme Bilimi ve Mühendisliği, 41400, Gebze, Kocaeli \\ scengiz@gtu.edu.tr, gencer@gtu.edu.tr, mtarakci@gtu.edu.tr, yazakli@gtu.edu.tr
}

(Geliş/Received: 05.06.2014; Kabul/Accepted: 14.07.2015)

ÖZET

İçerisine atomik olarak \% 1, 2, 4, 8 ve 16 bakır katkılandırılarak hazırlanan $\mathrm{Fe}-\mathrm{Cu}$ ikili alaşımları ve saf demir $1000^{\circ} \mathrm{C}^{\prime}$ de 3 saat süre ile kutu borlama işlemine tabi tutulmuştur. Elde edilen borür tabakanın faz içeriği, mikroyapısı, kimyasal kompozisyonu ve mikrosertliği, X-1şınları kıııımı, Yüzey Taramalı Elektron Mikroskobunda Enerji Dağılımlı X-ışınları Spektroskopisi (SEM-EDS) ve Vickers Mikrosertlik ölçümü ile karakterize edilmiştir. Altlıktaki Cu miktarının artmasıyla borür tabakasının morfolojisini değiştirdiği ve altlığa doğru taraksı bir yapıda büyüyen borür dişlerin incelerek daha da uzadığı tespit edilmiştir. Bakır atomları, ne $\mathrm{Cu}_{\mathrm{x}} \mathrm{B}_{\mathrm{y}}$ bileşiği oluşturmuş ne de oluşan demir borür tabakası içerisinde çözünmüştür. Ancak, borür dişlerinin büyüme yönüne paralel şekilde kümeleşerek bakırca zengin çökeltiler oluşturmuştur. Bu çökeltiler altlıktaki bakır miktarının artmasıyla hem kabalaşmış hem de miktarı artmıştır. Altlıktaki bakır miktarındaki artışa bağlı olarak borca zengin FeB fazının oluşumu desteklenmiş ve toplam borür tabaka kalınlığı artmış, ancak borür tabakanın sertliği düşmüştür.

Anahtar Kelimeler: Kutu borlama, $\mathrm{FeB}, \mathrm{Fe}_{2} \mathrm{~B}, \mathrm{Fe}-\mathrm{Cu}$ alaşımı, Borür tabaka morfolojisi

\section{INFLUENCE OF COPPER AMOUNT ON THE PACK BORONIZING BEHAVIOUR OF Fe-Cu BINARY ALLOYS}

\begin{abstract}
The Fe-Cu binary alloys prepared with the addition of 1, 2, 4, 8 and 16 at. \% copper along with pure iron were pack boronised at $1000^{\circ} \mathrm{C}^{\prime}$ for $3 \mathrm{~h}$. The microstructure, chemical composition, phase contents and microhardness of the formed boride layers were characterized by means of XRD, (Scanning Electron Microscopy-Energy Dispersive X-ray Diffraction) SEM-EDS and Vickers Microhardness measurements. The increasing amount of $\mathrm{Cu}$ in the $\mathrm{Fe}-\mathrm{Cu}$ alloys resulted in change of boride morphology and boride crystals growing towards the

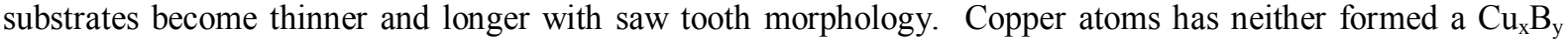
compound nor made a solid solution in Fe-B. However, copper rich precipitates were accumulated parallel to the growth direction of the boride crystals. The amount and size of these precipitates increased with the increase of $\mathrm{Cu}$ in $\mathrm{Fe}-\mathrm{Cu}$ alloys. The boron rich $\mathrm{FeB}$ phase formation was favored and total boride layer thickness increased though the hardness of the boride layer decreased with the increase of $\mathrm{Cu}$ in the substrates.
\end{abstract}

Keywords: Pack boriding, $\mathrm{FeB}, \mathrm{Fe}_{2} \mathrm{~B}, \mathrm{Fe}-\mathrm{Cu}$ alloy, Boride layer morphology

\section{GİRIŞ (INTRODUCTION)}

Borlama işlemi, demir esaslı ve birçok demir dışı malzemeye çok yaygın şekilde uygulanan bir termokimyasal yüzey sertleştirme işlemidir [1-12]. Bu işlemde, malzeme yüzeyinde yüksek sıcaklıkta borür bileşikleri oluşturularak belirli kalınlıkta sert bir tabaka elde edilir. $\mathrm{Bu}$ borür tabakasının; yüksek sertliğe, yüksek korozyon ve oksidasyon direncine, yüksek sıcaklıkta düşük sürtünme katsayısına sahip olması bu yöntemin en önemli avantajlarındandır [1, $6,8,11,13-17]$. Malzeme yüzeyinde oluşan borür tabakasının özelliklerini etkileyen temel parametreler; borlama işlem süresi ve sıcaklığı, kullanılan bor kaynağının bor konsantrasyonu ve altlık malzemenin kimyasal bileşimidir $[8,18-22]$. Bu değişkenlerin etkisi üzerine çok sayıda çalışma mevcuttur. Ancak, altlık malzemenin kimyasal bileşiminin borlama sonucu oluşan tabakanın özelliklerini belirleyici olduğu açık bir şekilde raporlanmasına rağmen, altlık 
malzemedeki alaşım elementlerinin yalın etkisini belirleyecek sistematik çalışmalar kısıtlıdır. $\mathrm{Bu}$ kapsamda Fe-M (M= Alaşım elementi) ikili alaşımları oluşturularak, alaşım elementlerinin demire ilavesi ile bu malzemenin borlama davranışı ve oluşan borür tabakanın özelliklerine etkisi araştırılmıştır. Yapılan bir çalışmada ağırlıkça \% 4 ve \% 12 krom, demire ilave edilerek altlıktaki artan krom miktarının borür tabaka kalınlığını düşürdüğü ve borür tabakasının morfolojisini taraksı yapıdan düz bir yapıya dönüştürdüğü raporlanmıştır. Aynı çalışmada ağırlıç̧a \% 4 ve \% 14 nikel, demire ilave edilmiş ve artan nikel miktarının borür tabaka kalınlığını düşürdüğü ancak borür tabakasının taraksı yapısını kısmen bozduğu rapor edilmiştir [23]. Bir başka çalışmada saf demire atomik olarak \% 1-16 Mn katılarak Fe-Mn ikili alaşımları hazırlanmış ve artan Mn miktarının oluşan borür tabakasının morfolojisini ve tabaka kalınlığını etkilemediği tespit edilmiştir. Ayrıca, $\mathrm{FeB}$ ve $\mathrm{Fe}_{2} \mathrm{~B}$ fazlarına ilave olarak atomik \% $16 \mathrm{Mn}$ içeren alaşımda $\mathrm{MnB}_{2}$ fazı görülmüştür [4]. Titanyumun saf demire ilavesiyle borlama davranışına etkisinin incelendiği çalışmada ise altlıktaki titanyum miktarının artmasıyla birlikte borür tabaka kalınlığ düşmüş ve testere dişli morfoloji kaybolmuştur. FeB, $\mathrm{Fe}_{2} \mathrm{~B}$ 'den oluşan borür tabakası içerisinde gömülü $\mathrm{TiB}_{2}$ çökeltileri ve bu çökeltilerden oluşan bir geçiş bölgesinin olduğu ve borür tabaka sertliğinin arttığ rapor edilmiştir [5]. Fe-V ikili alaşımlarının (at. \% 0,5-16) borlanması üzerine yapılan bir başka çalışmada vanadyumun, titanyuma benzer bir etkiye sahip olduğu ve hem $\mathrm{Ti}$ hem de $\mathrm{V}$ miktarının artmasıyla borür tabakada $\mathrm{FeB} / \mathrm{Fe}_{2} \mathrm{~B}$ 'nin arttığ her iki çalışmada da belirtilmiştir $[5,6]$. Demire katılan atomik \% 8 oranındaki silisyum elementinin borür tabakasında çözünmediği ve borür tabakası-altlık arasındaki bölgede zenginleşen silisyum, taraksı morfolojiye sahip borür tabakasının yapısını değiştirdiği bir başka çalışmada rapor edilmiştir [10]. Literatürde bakırın demire ilavesinin borlanma davranışına etkisiyle ilgili bir çalışmaya rastlanmamıştır. Ağırlıkça \% 0,01, 0,3 ve 0,98 bakır içeren küresel grafitli dökme demirlerin borlanması ile ilgili yapılan çalışmada, bakırın borür tabaka kalınlığını düşürdüğü ve sadece $\mathrm{Fe}_{2} \mathrm{~B}$ 'den oluşan borür tabakasının oluşmasına neden olduğu raporlanmıştır [22]. Ancak, kullanılan bu altlık malzeme içerisinde var olan diğer alaşım elementlerinin de borlama davranışına etkisinden ve bakır oranı farkının düşük olmasından dolayı meydana gelen değişimi sadece bakıra hamletmek zordur. Ayrıca, bakırda bor çözünürlüğünün oldukça düşük olması nedeniyle özellikle pasta borlama işleminde seçilmiş bölgelerin borlanması gerçekleştirilebilmektedir. $\mathrm{Bu}$ işlem borlanmaması istenen bölgelerin bakır kaplanması yoluyla yapılmaktadır [24].

Dolayısıyla, bu çalışmada bakırın demirin borlama davranışına etkisinin belirgin bir şekilde ortaya çıkarılması amacıyla, hazırlanan sentetik $\mathrm{Fe}-\mathrm{Cu}$ ikili alaşımların yüzeylerinde oluşturulan borür tabakasına bakırın etkisi araştırılmıştır. Oluşturulan bu borür tabakası XRD, SEM, SEM-EDS ve mikrosertlik cihazları ile karakterize edilmişlerdir.

\section{DENEYSEL ÇALIŞMA (EXPERIMENTAL STUDY)}

Saf demir $\left(\begin{array}{lll}\% & 99,97)\end{array}\right)$ ve saf bakır $\left(\begin{array}{ll}\% & 99,5\end{array}\right)$ kullanılarak, atomik olarak \% 1, 2, 4, 8, $16 \mathrm{Cu}$ içerecek şekilde $\mathrm{Fe}-\mathrm{Cu}$ ikili alaşımları hazırlanmış ve sirasiyla $\mathrm{Fe}-1 \mathrm{Cu}, \mathrm{Fe}-2 \mathrm{Cu}, \mathrm{Fe}-4 \mathrm{Cu}, \mathrm{Fe}-8 \mathrm{Cu}, \mathrm{Fe}-16 \mathrm{Cu}$ olarak adlandırılmıştır. Hedeflenen alaşımları hazırlamak üzere uygun miktardaki $\mathrm{Fe}$ ve $\mathrm{Cu}$ parçacıkları ark ergitme haznesine yerleştirilmiştir. Ark ergitme haznesi, $1 \times 10^{-5}$ mbar seviyesine vakumlandıktan sonra, saf argon gazı $(\% 99,998)$ ile doldurulmuş ve ergitme/katılaştırma işlemi yapılmıştır. Homojenliği sağlamak için ergitme/katılaştırma işlemi numune alt üst edilerek tekrarlanmıştır. İşlem sonunda elde edilen $\mathrm{Fe}-\mathrm{Cu}$ ikili alaşımları dilimlenerek $10 \mathrm{~mm}$ x $10 \mathrm{~mm}$ × $5 \mathrm{~mm}$ boyutlarında numuneler elde edilmiştir. Numunelerin geniş olan her iki yüzü 80-1200 nolu silisyum karbür zımparalar ile zımparalanmış ve sırasıyla 6,3 ve $1 \mu \mathrm{m}$ tane boyutların sahip alümina ile parlatılarak borlama işlemine hazır hale getirilmiştir. Karşılaştırma amacıyla kullanılacak aynı boyuttaki saf demir numunenin yüzeyi de benzer şekilde hazırlanmıştır. Saf demir ile $\mathrm{Fe}-\mathrm{Cu}$ alaşımları ticari Ekabor II tozu (Bortec) içeren seramik pota içerisine pota duvarlarından ve birbirlerine eşit uzaklıkta olacak şekilde yerleştirilmiştir. Yüksek sicaklıkta muhtemel oksitlenmeyi engellemek amaciyla potanın üst kısmına Ekrit tozu (Bortec) eklenmiş ve potanın ağzı sıkı bir şekilde kapatılmıştır. Borlamaya hazır saf Fe ve $\mathrm{Fe}-\mathrm{Cu}$ numunelerin bulunduğu seramik potalar programlanabilir kutu firın içerisine yerleştirilmiştir. Fırın 30 dakika içerisinde $1000 \pm 5^{\circ} \mathrm{C}$ ' ye isıtılarak, numuneler, bu sicaklıkta 3 saat süreyle borlama işlemine tabi tutulmuştur. Borlama işlemi bittiğinde firın kapağı hemen açılarak, numunelerin oda sıcaklığına kadar soğuması sağlanmıştır. Borlanan numunelerin yüzeyleri muhtemel borlama tozu kalıntılarını gidermek üzere mekanik olarak temizlenmiştir. Borlanmış numunelerin yüzeylerinde oluşan borür tabakasının faz analizi, Bruker D8 X1şınları kırınımı cihazında, $\mathrm{Cu}-\mathrm{K} \alpha$ 1şını ve $20^{\circ}-100^{\circ}$ arası $2 \%$ dakika hızla taranarak yapılmıştır. Kesitten mikroyapı incelemesi amacıyla borlanmış numuneler hassas elmas kesici ile ikiye kesilmiş ve borür tabaka kesiti açığa çıkacak şekilde reçine kalıba alınmıştır. Reçine kalıba alınan numuneler 80-1200 nolu silisyum karbür zımparalar ile zımparalanmıș ve 6, 3 ve $1 \mu \mathrm{m}$ tane boyutuna sahip alümina ile parlatılmıştır. Kesitten mikroyapı incelemesi ve kimyasal analiz için Philips XL-30 SEM ve SEMEDS kullanılmıştır. Borür tabakalarının mikrosertlik değerleri Mitutoyo HM-200 Vikers mikrosertlik cihazı ile 30 gr yükün 10 sn süreyle uygulanmasıyla tabaka dış yüzeyinden altlığa doğru tabaka kalınlığı boyunca ölçülmüştür. Sertlik değerlerinin tespiti için 


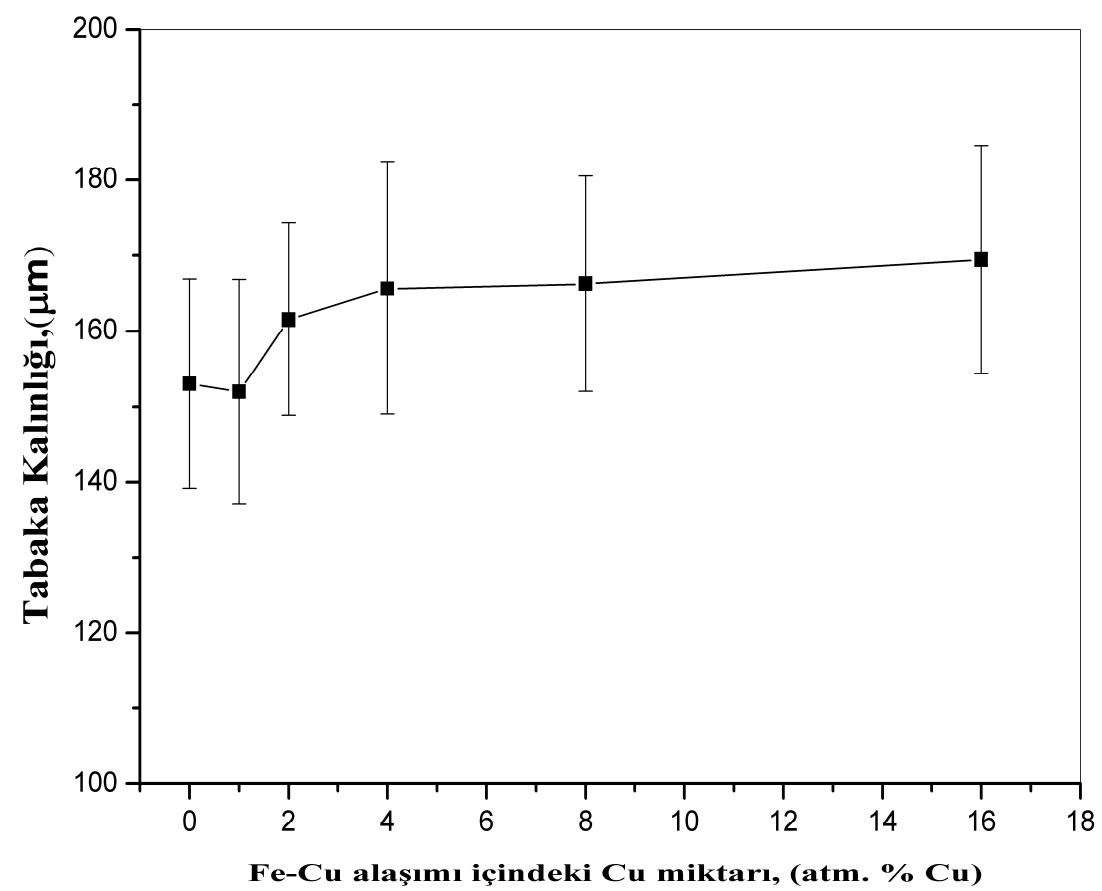

Şekil 1. Fe-Cu alaşımlarının borlanması $\left(1000{ }^{\circ} \mathrm{C}, 3\right.$ saat) sonucu oluşan borür tabaka kalınlığının altlıktaki $\mathrm{Cu}$ miktarına bağlı olarak değişimi (The change in boriding $\left(1000{ }^{\circ} \mathrm{C}, 3 \mathrm{~h}\right)$ layer thickness with copper content in $\mathrm{Fe}-\mathrm{Cu}$ substrate)

en az 3 Vickers izi oluşturularak, ortalama sertlik değeri elde edilmiştir. Tabaka kalınlığı kesitten alınan SEM fotoğrafları kullanılarak borür tabakasının en diş yüzeyi ile borür tabakasının en uç noktası arasındaki mesafe ölçülerek ve en az 20 ölçümün ortalaması alınarak tespit edilmiştir.

\section{DENEYSEL SONUÇLAR (EXPERIMENTAL RESULTS)}

\subsection{Tabaka Kalınlığı (Layer Thickness)}

Şekil 1'de Fe-Cu ikili alaşımları ve saf demirin 1000 ${ }^{\circ} \mathrm{C}$ ' de 3 saat borlanması sonucu oluşan borür tabaka kalınlığının altlıktaki bakır miktarına bağlı olarak değişimi verilmiştir. Saf $\mathrm{Fe}$ üzerinde oluşturulan tabakanın kalınlığ $155 \pm 15 \mu \mathrm{m}$ iken Fe-16Cu ikili alaşımı üzerinde oluşan tabakanın kalınlığı yaklaşık olarak $167 \pm 15 \mu \mathrm{m}$ ' dur. Saf demir içine at. \% $4 \mathrm{Cu}$ miktarına kadar ilave edilen bakırın tabaka kalınlığını bir miktar arttırdığı ancak daha fazla bakır ilavesi tabaka kalınlığı üzerinde dikkate değer bir etkisi görülmemektedir.

\subsection{XRD Faz Analizi (XRD Analysis)}

Şekil 2'de Fe-Cu ikili alaşımları ve saf demirin 1000 ${ }^{\circ} \mathrm{C}$ 'de 3 saat borlanması sonucu oluşan tabakanın yüzeylerinden alınmış XRD spektrumları verilmiştir. Tabakaların tümünde $\mathrm{FeB}$ ve $\mathrm{Fe}_{2} \mathrm{~B}$ fazları tespit edilmiş olup, bu fazlarında yöne bağlı olarak tercihli bir büyüme görülmemektedir. Yüksek bakır içeren
$\mathrm{Fe}-\mathrm{Cu}(\mathrm{Fe}-8 \mathrm{Cu}$ ve $\mathrm{Fe}-16 \mathrm{Cu})$ ikili alaşımlarına ait XRD spektrumlarında elementel bakırın varlığ $1(2 \theta=$ $43,5^{\circ}$ ) söz konusudur. Fe-16Cu'ya ait spektrumdaki bakıra ait pikin şiddeti $\mathrm{Fe}-8 \mathrm{Cu}$ 'ya ait pikten daha yüksektir. Altlıktaki $\mathrm{Cu}$ elementi miktarındaki artışla beraber $\mathrm{Fe}_{2} \mathrm{~B}$ fazına ait piklerin şiddetleri zayıflarken, FeB fazına ait piklerin şiddetleri artmıştır.

\subsection{Borür Tabakalarının Mikroyapı İncelenmesi (Microstructure Analysis of The Boride Layers)}

$\mathrm{Fe}-\mathrm{Cu}$ ikili alaşımları ve saf demirin $1000{ }^{\circ} \mathrm{C}$ 'de 3 saat borlanması sonucu oluşan tabakanın kesitten alınan SEM görüntüleri Şekil 3'de verilmiştir. Saf demir üzerinde oluşan borür tabakasının taraksı yapıda ve tabaka diş yüzeyinin göreceli olarak düz olduğu görülmektedir (Şekil 3a). Saf demir içerisine ilave edilen bakır elementi miktarındaki artışla borür tabakasını oluşturan taraksı/dişli yapıdaki diş kalınlıklarının inceldiği ve bu dişlerin boylarının göreceli olarak arttığı SEM görüntülerinden anlaşılmaktadır (Şekil 3b-g). Ayrıca Fe-Cu ikili alaşımı içerisindeki bakır elementi miktarındaki artış ile beraber borür tabakasının en diş kısmının oldukça gözenekli, buna karşın altlığa doğru gidildikçe daha yoğun olduğu görülmektedir. Borür tabakasının iç kısmındaki gözenek miktarı $\mathrm{Fe}-\mathrm{Cu}$ ikili alaşımı içerisine katkılandırılan bakırın artması ile artmaktadır. Fe-Cu ikili alaşımı üzerinde oluşturulan borür tabakası içinde mevcut olan bu gözenekler dışında, borür tabaka içinde borür kristallerine paralel şekilde açık renkli çökeltiler görülmektedir (Şekil 3c). 

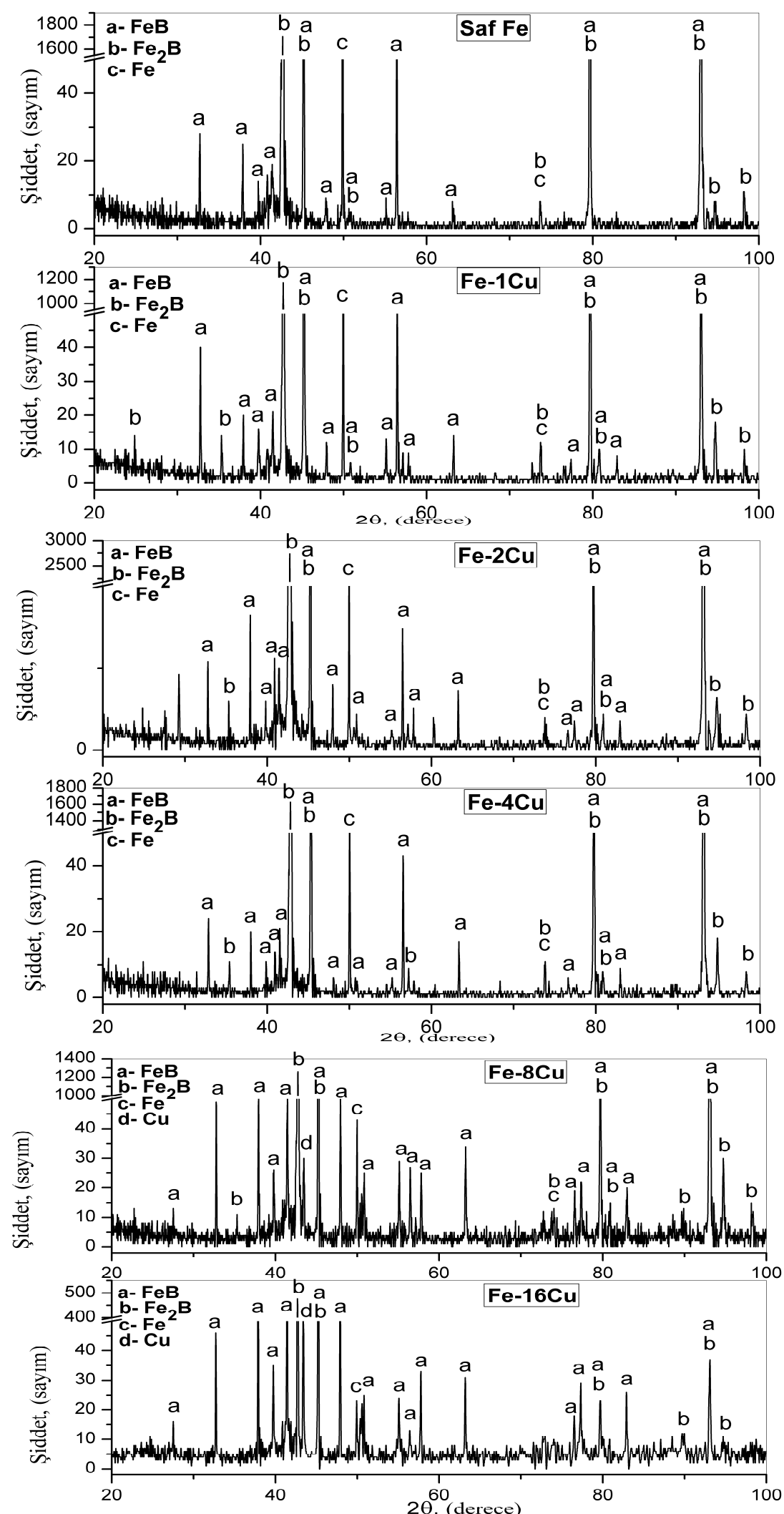

Şekil 2. Borlanmış $\left(1000{ }^{\circ} \mathrm{C}, 3\right.$ saat) $\mathrm{Fe}-\mathrm{Cu}$ alaşımları ve saf demirin yüzeyinden alınan XRD spektrumu (Surface XRD spectrum of borided $\left(1000^{\circ} \mathrm{C}, 3 \mathrm{~h}\right.$ ) Fe-Cu alloys and pure $\mathrm{Fe}$ ) 

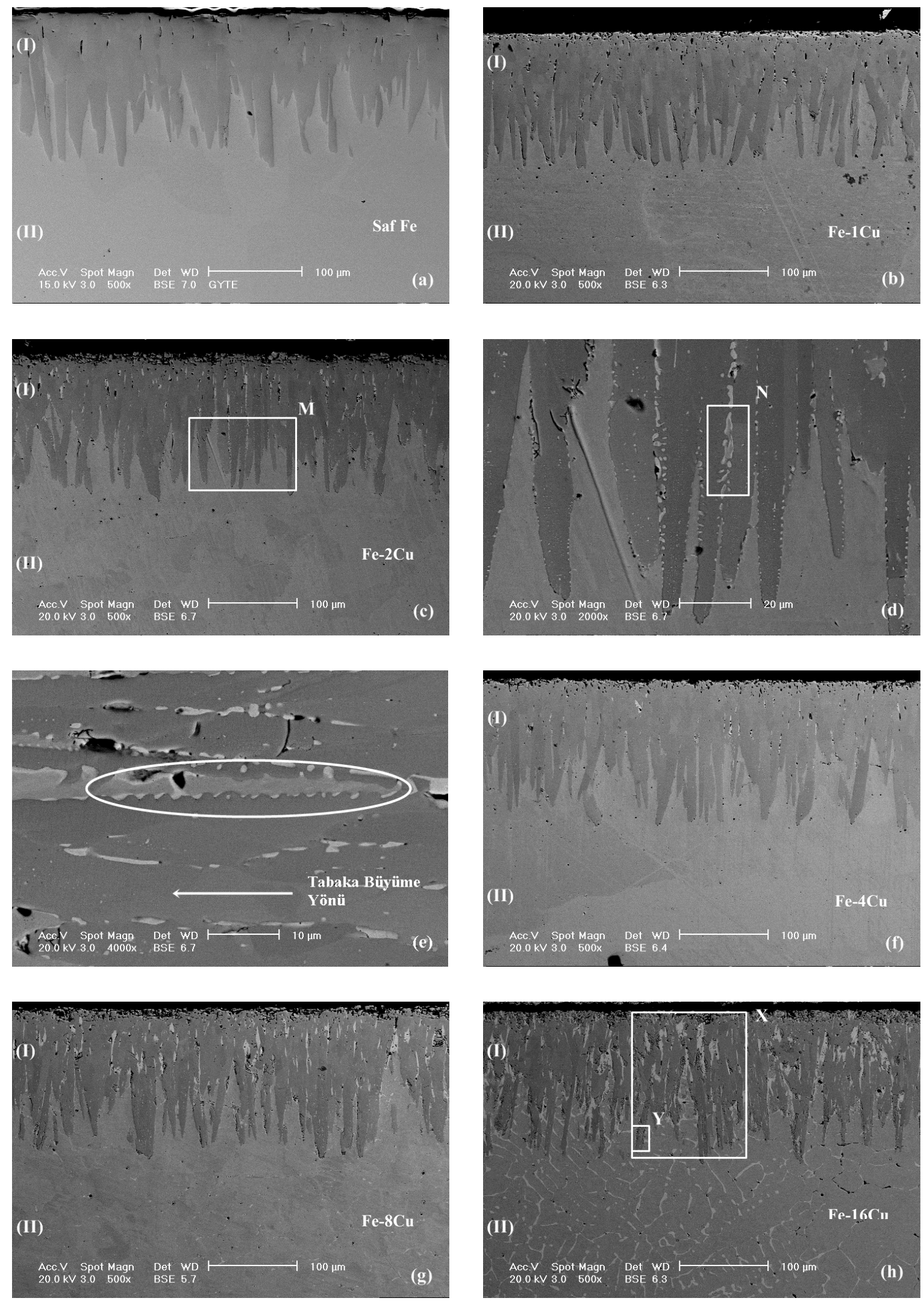


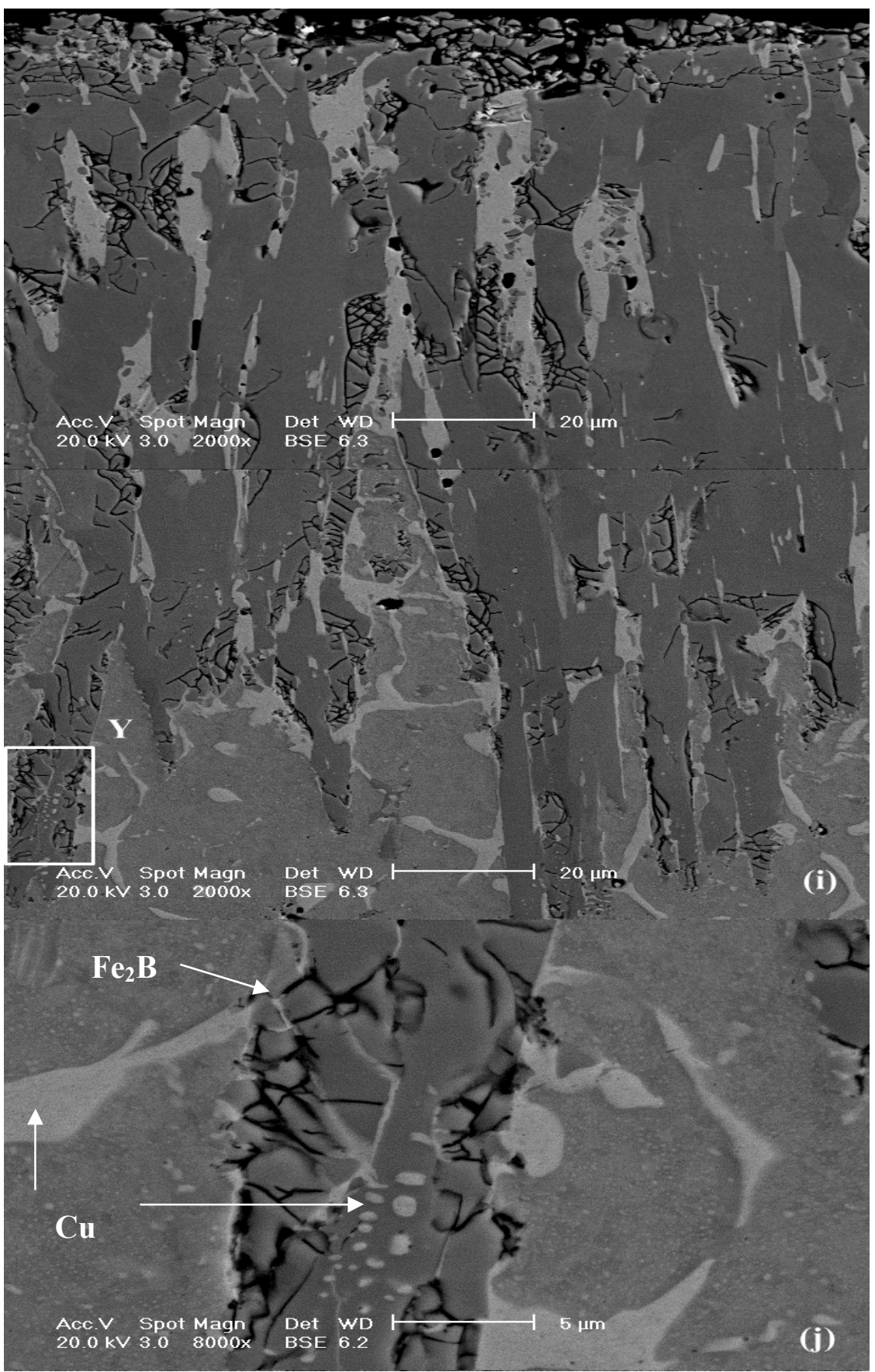

Şekil 3. Fe-Cu alaşımları ve saf Fe altlıklar üzerinde $1000{ }^{\circ} \mathrm{C}$ ' de 3 saat süreyle borlama sonucu oluşan borür tabakaların kesitten SEM görüntüsü; (a) Saf Fe, (b) Fe-1Cu, (c) Fe-2Cu, (d) Şekil 3c' de 'M' ile işaretlenen bölge, (e) Şekil 3c' de 'N' ile işaretlenen bölge, (f) Fe-4Cu, (g) Fe-8Cu, (h) Fe-16Cu, (i) Şekil 3h' de ' $\mathrm{X}$ ' ile işaretlenen bölge, (j) Şekil 3h-i' de ' $\mathrm{Y}$ ' ile işaretlenen bölge (Cross sectional SEM micrograph of boride $\left(1000{ }^{\circ} \mathrm{C}, 3 \mathrm{~h}\right.$ ) layers formed on $\mathrm{Fe}-\mathrm{Cu}$ alloys and pure $\mathrm{Fe}$; (a) Pure $\mathrm{Fe}$, (b) $\mathrm{Fe}-1 \mathrm{Cu}$, (c) $\mathrm{Fe}-2 \mathrm{Cu}$, (d) the region marked as ' $\mathrm{M}$ ' in Fig. 3c, (e) a typical region marked as 'N' in Fig. 3d, (f) Fe-4Cu, (g) Fe-8Cu, (h) Fe$16 \mathrm{Cu}$, (i) the region marked as ' $\mathrm{X}$ ' in Fig. $3 \mathrm{~h}$ and (j) the region marked as ' $\mathrm{Y}$ ' in Fig. 3h)

$\mathrm{Bu}$ açık renkli çökeltilerin miktarı ve büyüklüğü genellikle borür kristallerin büyüme yönüne paralel olmak üzere altlıktaki bakır miktarı ile artmaktadır (Şekil 3f-h). Şekil 3c'de 'M' ile işaretlenmiş bölgenin büyütülmüş görüntüsü Şekil $3 \mathrm{~d}$-e'de verilmiştir. Borür tabakaların içerisindeki açık renkli çökeltilerin yanında, Şekil 3d'de 'N' ile işaretlenen borür kristalleri ile matris arasında yoğun bir şekilde açık renkli çökeltiler mevcuttur. Bu çökeltilerin varlığ Şekil 3e'de tipik olarak daha yüksek büyütmede alınan kesit görüntüsünde verilmiştir. Şekil 3e incelendiğinde bu çökeltilerin borür dişleri ile matris 
arasında bulunmasının yanında borür dişleri içerisinde gömülü olarak da bulunduğu ve borür kristallerine paralel olarak yönlendiği anlaşılmaktadır. Elips içerisine alınarak gösterildiği gibi, bu çökeltilerin bulunmadığı veya süreklilik göstermediği kısımlarda borür dişlerinin yanal olarak da büyüdüğü anlaşılmaktadır (Şekil 3e). Benzer çökeltiler, daha yüksek bakır içeren alaşımların $(\mathrm{Fe}-4 \mathrm{Cu}$ ve $\mathrm{Fe}-8 \mathrm{Cu})$ borür tabakasında da oluşmuştur (Şekil 3f-g). Borlanmış $\mathrm{Fe}-16 \mathrm{Cu}$ numunesine ait kesit SEM görüntüsü (Şekil 3h) incelendiğinde taraksı yapıdaki borür dişlerinin kesitlerinin daha da inceldiği ve borür tabaka dış yüzeyinin gözenek miktarının arttığı görülmektedir. Açık renkli çökeltiler $\mathrm{Fe}-16 \mathrm{Cu}$ numunesi için de söz konusu olup, bu çökeltiler kabalaşmıştır ve $\mathrm{Fe}-8 \mathrm{Cu}$ borür tabakasında olduğu gibi borür dişlerinin büyüme yönüne paralel şekilde gelişmiştir. Açık renkli çökeltilerin $\mathrm{Fe}-16 \mathrm{Cu}$ altlık alaşım mikroyapısında da rastgele yönlendiği görülmektedir. Borlanmış Fe-16Cu alaşımına ait kesit SEM görüntüsünde $\mathrm{X}$ ve $\mathrm{Y}$ ile işaretlenen bölgelerin daha yüksek büyütmede alınan SEM görüntüleri sırasıyla Şekil 3i ve Şekil 3j'de verilmiştir. Şekil 3i incelendiğinde tabaka dış bölgesinin gözenekli yapısı daha net görülmekte olup tabaka yüzeyine paralel çatlakların olduğu da görülmektedir. Ayrıca borür tabakası içerisinde açık renkli çökeltilerin küçük adacıklar şeklinde olduğu ve borür tabakası dişlerine paralel şekilde büyüdüğü daha net görülmektedir (Şekil 3i). Borür tabakası içerisinde yer yer rastgele yönlenmiş koyu renkli çatlak benzeri veya çizgisel gözenekli yapılar da bu mikrograflarda görülmektedir (Şekil 3i). Bu tipik yapılar (Şekil 3h-i'de Y ile işaretli bölge) daha yüksek büyütme ile alınan SEM görüntüsünde daha belirgin bir şekilde görülmekte olup, $\mathrm{Fe}_{2} \mathrm{~B}$ tabakası üzerindeki açık renkli çökeltiler sürekli ve süreksiz adacık şeklinde bulunmaktadır. Benzer çökeltiler ana matriste bulunmaktadır.

\subsection{Borür Tabakasının Elementel (SEM-EDS) Analizi (Elemental Analysis (SEM-EDS) of The Boride Layers)}

Şekil 4' de, $1000^{\circ} \mathrm{C}^{\prime}$ de 3 saat süre ile borlanmış Fe$16 \mathrm{Cu}$ ikili alaşımına ait kesit SEM görüntüsü ve borür tabakasının SEM-EDS spektrumları verilmiştir. Borür tabakasının dışından atlığa doğru bir çizgi boyunca alınan SEM-EDS spektrumu Şekil 4b'de verilmiştir. Çizgisel elementel analiz sonuçlarına göre; bor konsantrasyonunun, tabakanın diş kısmından altlığa doğru bir çizgi boyunca, çok belirgin olmasa da azaldığı görülmüştür.

Aynı çizgi boyunca, borür tabakasının dış yüzeyinden altlık yönüne gittikçe $\mathrm{Fe}$ konsantrasyonu çok az artmaktadır. Tabaka kalınlığı boyunca ortalama $\mathrm{Cu}$ miktarı değişmezken, altlıktaki ortalama $\mathrm{Cu}$ miktarı tabakaya göre daha yüksektir. Ancak, çökelti şeklindeki açık renkli yapılarda Fe konsantrasyonun çok belirgin bir şekilde düştüğü, buna karşın $\mathrm{Cu}$ elementi konsantrasyonun belirgin şekilde arttığ tespit edilmiştir (Şekil 4b). Çizgi SEM-EDS analizine ilave olarak, borür tabakası içerisindeki açık renkli bu çökeltileri (K1) ve çevresindeki koyu renkli bölgenin (K2) noktasal SEM-EDS analizi yapılmış ve elde edilen sonuçlar sırasıyla Şekil 4c ve 4d'de verilmiştir. $\mathrm{K} 1$ ile gösterilen noktadan alınan elementel analiz sonucuna göre yüksek miktarda bakıra ilave olarak az miktarda demir bulunduğu ve bor elementinin ise bulunmadığ1 tespit edilmiştir (Şekil 4c). K2 noktasında ise bakır elementi hiç bulunmazken, yüksek miktarda demir ve bor elementlerinin bulunduğu anlaşılmaktadır (Şekil 4d).

\subsection{Tabaka Sertliği (Layer Hardness)}

Şekil 5'de Saf Fe ve Fe-Cu ikili alaşımlarının 1000 ${ }^{\circ} \mathrm{C}$ ' de 3 saat süreyle borlanması sonucu oluşan borür tabakasının dış yüzeyinden altlığa doğru mesafeye bağlı mikrosertlik değerleri verilmiştir. Borür tabakasının en yüksek sertlik değeri yaklaşık 2100 HV iken en düşük sertlik değeri yaklaşık $1300 \mathrm{HV}$ olarak ölçülmüştür. Altlık malzemelerin mikrosertlik değerleri ise $110 \mathrm{HV}$ ile $175 \mathrm{HV}$ arasında değişmektedir. Her bir malzemenin borür tabakasının mikrosertlik değerlerinde sapma olmakla beraber borür tabakalarının mikrosertlik değerlerinin tabaka kalınlığı boyunca değişmediği görülmektedir. Saf demir üzerinde oluşan borür tabakasının ortalama mikrosertlik değerinin diğer bakırlı alaşımların sertliklerinden daha yüksek olduğu görülmektedir. Altlıktaki bakır miktarının artmasıyla ortalama borür tabaka sertliği düşme eğilimi göstermekte ve mikrosertlik değerlerindeki sapma miktarı artmaktadır (Şekil 5). Ayrıca borür tabakası ile altlık arasında mikrosertlik değerlerindeki düşüşün keskin olduğu görülmekte olup mikrosertlik açısından bir geçiş bölgesi söz konusu değildir.

\section{TARTISTMA (DISCUSSION)}

$\mathrm{Fe}-\mathrm{Cu}$ ikili alaşımları ve saf $\mathrm{Fe} 1000^{\circ} \mathrm{C}$ 'de 3 saat süreyle kutu borlama işlemine tabi tutulmuş ve bu malzemelerin yüzeylerinde taraksı/dişli bir morfolojiye sahip borür tabakası elde edilmiştir. Altlıktaki bakır elementi miktarına bağlı olarak bu taraksı/dişli yapının morfolojisinde değişmeler gözlenmiştir. XRD sonuçları incelendiğinde borür tabakasının $\mathrm{FeB}$ ve $\mathrm{Fe}_{2} \mathrm{~B}$ fazlarından oluştuğu görülmüştür. $\mathrm{Bu}$, demir esaslı malzemelerin borlanmasıda tipik olarak karşılaşılan bir durum olup, borlama şartlarına bağlı olarak $\mathrm{FeB} / \mathrm{Fe}_{2} \mathrm{~B}$ oranı değişmektedir. $\mathrm{Bu}$ oran, bor konsantrasyonunun yüksek olduğu şartlarda artmaktadır.

XRD spektrumları incelendiğinde saf Fe içerisine ilave edilen bakır elementi miktarına bağlı olarak FeB miktarının arttığı anlaşılmaktadır. Altlığın atomik \% 8 ve üzeri bakır içermesi durumunda, XRD spektrumunda elementel bakıra ait piklerin olduğu görülmüştür. 


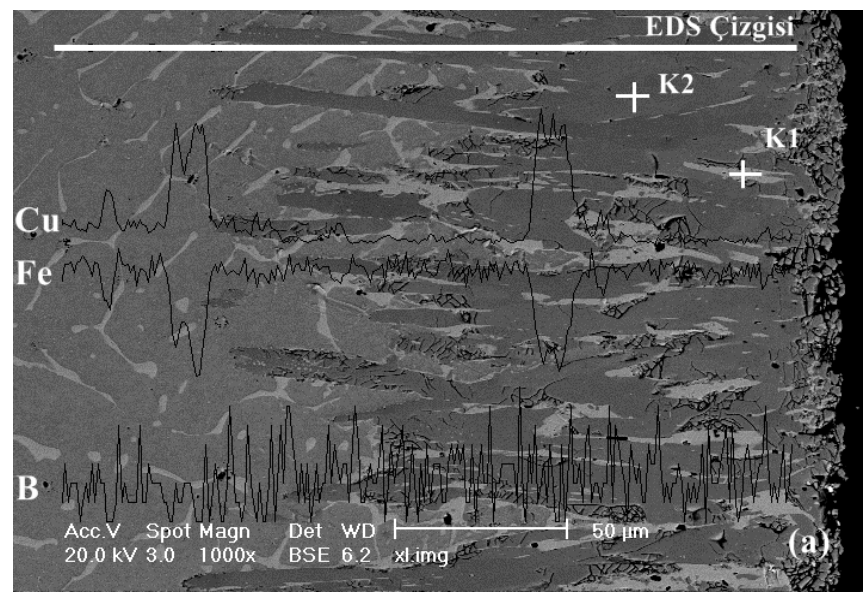

(b)
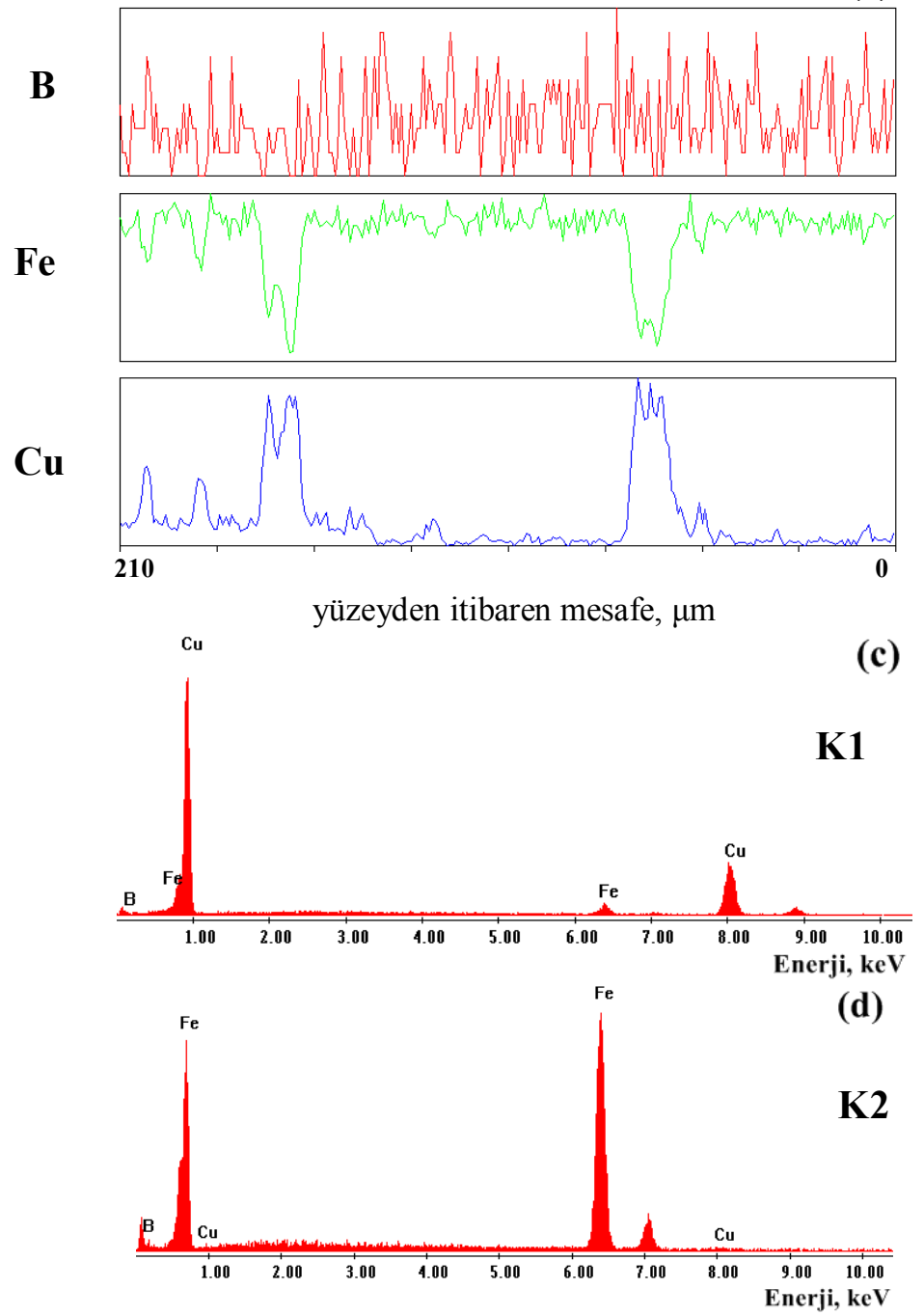

Şekil 4. Borlanmış $\left(1000^{\circ} \mathrm{C}, 3\right.$ saat) $\mathrm{Fe}-16 \mathrm{Cu}$ ikili alaşımına ait kesit SEM görüntüsü ve SEM-EDS spektrumları; (a) Kesit SEM görüntüsü ve çizgi SEM-EDS spektrumu, (b) Çizgi SEM-EDS spektrumu, (c) K1 noktasindan SEM-EDS spektrumu, (d) K2 noktasından SEM-EDS spektrumu (Cross sectional SEM micrograph and related SEM-EDS spectra for the borided $\left(1000^{\circ} \mathrm{C}, 3 \mathrm{~h}\right.$ ) $\mathrm{Fe}-16 \mathrm{Cu}$ binary alloy; (a) SEM micrograph and line SEM-EDS spectrum, (b) Line SEM-EDS spectrum, (c) Spot SEM-EDS for K1 in Fig. 4a and (d) Spot SEM-EDS for K2 in Fig. 4a) 


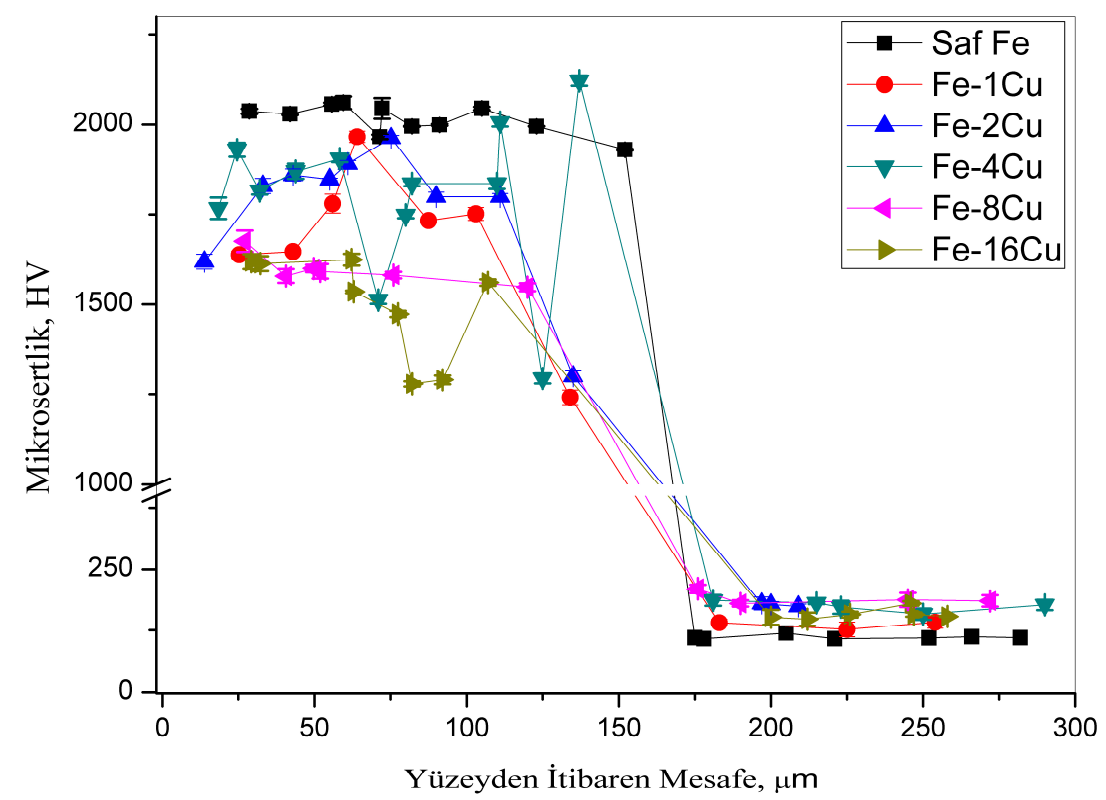

Şekil 5. Borlanmış $\left(100{ }^{\circ} \mathrm{C}, 3\right.$ saat $) \mathrm{Fe}-\mathrm{Cu}$ alaşımları ve saf demirin yüzeyinde oluşturulan tabakaların dış yüzeylerinden altlığa doğru mesafeye bağlı mikrosertlik değişimi (Microhardness profile from the boride layer surface towards the substrates for borided $\left(1000^{\circ} \mathrm{C}, 3 \mathrm{~h}\right) \mathrm{Fe}-\mathrm{Cu}$ alloys and pure $\left.\mathrm{Fe}\right)$

Yapılan kesitten SEM inceleme sonuçları bakır esaslı parçacıkların çökeltiler halinde borür tabakası içerisinde varlığı teyit edilmiştir. Ayrıca XRD spektrumunda görülmemesine rağmen $\mathrm{Fe}-2 \mathrm{Cu}$ altlığı üzerindeki borür tabakasında da bu bakırca zengin çözeltilerin var olduğu görülmüştür. $\mathrm{Bu}$ bakırca zengin çökeltilerin içerisinde çok az miktarda demir de bulunduğu çizgisel ve noktasal SEM-EDS sonuçlarından anlaşılmıştır. $\mathrm{Fe}-\mathrm{Cu}$ faz diyagramına göre, oda sıcaklığında demirin bakır içerisindeki çözünürlüğü çok çok düşük olmasına rağmen bu çökeltilerin demir elementi içeriyor oluşunun nedeni; numunelerin borlama sicaklılığ 1 olarak seçilen $1000^{\circ}$ C'den oda sıcaklığına hızlı soğutulmasıdır [25]. Yapilan incelemelerde $\mathrm{Fe}-2 \mathrm{Cu}$, hatta $\mathrm{Fe}-4 \mathrm{Cu}$ alaşımlarının ana matrisinde bu çökeltiler görülmemiş, sadece borür tabakası içerisinde irili ufaklı çökeltiler halinde bulunduğu anlaşılmıştır. $\mathrm{Bu}$ durum $\mathrm{FeB}$ ve $\mathrm{Fe}_{2} \mathrm{~B}$ borür fazlarının bakırı, bünyesinde yer alan katı eriyik olarak bulundurmadığ sonucunu doğrulamaktadır. Borür tabakadaki çökeltilerin miktarı ve boyutu altlık malzemedeki $\mathrm{Cu}$ miktarı ile artmaktadır. Bakırca zengin çökeltiler bor difüzyonunun yüzeyden matrikse doğru ilerlemesine etki etmemektedir. $\mathrm{Bu}$ sebeple borür tabakası dişlerinin altlığa doğru büyümesine bakırın etkisi olmamıştır. Ancak, borür tabakası içerisinde çözünmediği için bu borür bileşiklerinin çevresinde biriken sürekli ve süreksiz bakırca zengin çökeltiler, borun yanal (kristallerin büyüme yönüne dik) difüzyonuna fiziksel engel teşkil ederek borür tabakasının yanal büyümesini kısmen ya da tamamen engellemektedir. Altlıktaki bakır miktarı arttıkça kabalaşan, miktarı artan ve borür tabakası dişleri arasında sürekli hale gelen (borür tabakası büyüme yönünde yönlenen) bu bakırca zengin çökeltiler borun yanal difüzyonunu engelleyince altlığa doğru difüze olmasını tetiklemektedir. $\mathrm{Bu}$ da borür kristallerinin altlığa doğru hem incelmesine hem de daha derin nüfuz etmesine, sonuçta kaplama kalınlığının artmasına da neden olmaktadır. Ayrıca, yanal yönde kısıtlanan bor elementinin difüzyonu toplam difüzyon mesafesinin ve dolayısıyla borür tabakasının dış yüzeyinde bor konsantrasyonun artmasina ve böylece borür tabakasının dış yüzeyinde $\mathrm{FeB}$ miktarının göreceli olarak artmasına neden olmaktadır.

Benzer çalışmalar incelendiğinde borlanan $\mathrm{Fe}-\mathrm{Cu}$ ikili alaşımı, borlanan diğer Fe-M (M:Cr, Ni, Ti, V, Mn, Si) ikili alaşımlarından farklı bir davranış göstermektedir[4-6, 10, 20]. Yüksek oranlarda Cr, Ti ve $\mathrm{V}$ alaşım elementlerin Fe-M içerisinde bulunması elde edilen borür tabakasının taraksı/dişli yapı morfolojisini değiştirmiş ve tabaka-altlık geçiş bölgesini düzleştirdikleri belirtilmiştir $[5,6,20]$. Buna yanında bakır atomlarının borür tabakası içerisinde çözünmemesine karşın, gerek borür tabakasında gerekse geçiş bölgesinde, $\mathrm{Cr}$, Ti ve $\mathrm{V}$ elementleri ile borun oluşturduğu $\mathrm{M}_{\mathrm{x}} \mathrm{B}_{\mathrm{y}}$ bileşikleri, takip eden süreçte borun difüzyonunu engelleyerek hem borür tabakasının düzleşmesine hem de tabaka kalınlığının düşmesine sebep olduğu rapor edilmiştir $[5,6,20]$. Diğer bir çalışmada borlanan Fe-Si ikili alaşımlarında, Si atomları, borür tabakası-altlık geçiş bölgesinde birikerek silisyumca zengin bir geçiş bölgesi oluşturduğu ve borun altlık içine difüzyonunu engelleyerek borür tabakasının morfolojisini kısmen düzleştirip, kaplama kalınlığını düşürdüğü belirtilmiştir [26].

Mesafeye bağlı sertlik değerleri incelendiğinde $\mathrm{Fe}-\mathrm{Cu}$ ikili alaşımı içerisine katkılandırılan bakır elementi 
miktarındaki artışa bağlı olarak tabaka sertliğinin düşüş gösterdiği tespit edilmiştir. Genel olarak bakır miktarının artması ile Fe-Cu altlık sertliklerinde artışa rağmen, altlıktaki bakır miktarının borür tabakasının sertliğindeki düşüşün, borür tabakası içerisindeki bakır çökeltilerin kaplamayı zayıflatmasından ve makro çatlaklar oluşturmasından kaynaklandığı düşünülmektedir. Özellikle, borlanan $\mathrm{Fe}-16 \mathrm{Cu}$ numunesine ait farklı büyütmelerdeki SEM kesit resimleri incelendiğinde mikroyapıda borür tabakasında rastgele yönlenmiş çatlakların parlatma sırasında kolaylıkla yerinden ayrılan bakırca zengin çökeltilerden kaynaklandığı düşünülmektedir. Sertlik izi oluşturma sırasında bu çizgisel/hücresel boşluklar sertlik değerlerinin düşmesinin ana sebebidir. Ancak, bakırın yer yer ve sert borür kaplama kalınlığı boyunca bulunması yüksek sıcaklık uygulamaları için ilginç bir kompozit karakter sergileyebileceği düşünülmektedir. Zira $\mathrm{CuO}^{\prime}$ in yüksek sıcaklıklarda kendi kendine yağlama (self lubricating) özelliği olduğu bilinmektedir [27].

\section{SONUÇLAR (CONCLUSION)}

$\mathrm{Bu}$ çalışmada atomik olarak \% 1-16 Cu içeren $\mathrm{Fe}-\mathrm{Cu}$ ikili alaşımı ile saf demir $1000^{\circ} \mathrm{C}^{\prime}$ de 3 saat süre ile Ekabor II tozu ile katı ortamda borlanmış ve aşağıdaki sonuçlara ulaşılmıştır;

Saf demir içerisine bakır elementi ilavesi artışı ile beraber tabaka kalınlığı artmıştır.

Altlıktaki bakır miktarındaki artışa bağlı olarak borca zengin FeB fazının oluşumu artmıştır.

Altlıktaki bakır miktarının artması ile borür tabakasının morfolojisi değişmiş ve tabaka-altlık geçiş bölgesinde oluşan taraksı/dişli yapıdaki borür tabakası diş kalınlığı incelerek daha da uzamıştır.

Saf Fe içerisine bakır elementi katkısı ile beraber tabaka sertliği düşmüştür. Saf Fe ve $\mathrm{Fe}-16 \mathrm{Cu}$ alaşım üzerindeki tabaka sertliği sırasıyla yaklaşık olarak $2100 \mathrm{HV}$ ve $1350 \mathrm{HV}$ olarak ölçülmüştür.

Bakır atomları, $\mathrm{Cu}_{\mathrm{x}} \mathrm{B}_{\mathrm{y}}$ bileşiği veya demir borür ile herhangi bir katı ergiyik oluşturmamış, borür tabakasının büyüme yönüne paralel olarak kümeleşerek borür tabakası içerisinde bakırca zengin çökeltiler oluşmuştur. Bu çökeltiler altlıktaki bakır miktarının artması ile artmış ve kabalaşmıştır.

\section{KAYNAKLAR (REFERENCES)}

1. O. Çulha, M. Toparlı, S. Şahin, ve T. Aksoy, "Characterization and determination of FexB layers' mechanical properties," Journal of Materials Processing Technology, Cilt 206, No 1-3, 231-240, 2008.
2. Atar, E., E.S. Kayalı ve H. Çimenoglu, Surface "Modification of Ti6Al4V Alloy by Pack Boriding," Tms 2009 138th Annual Meeting \& Exhibition - Supplemental Proceedings, Cilt 3: General Paper Selections, 601-606, 2009.

3. I. Campos-Silva, N. Lopez-Perrusquia, M. OrtizDominguez, U. Figueroa-Lopez ve E. HernandezSanchez, "Measurement of Fracture Toughness in AISI 1018 Borided Steels by Vickers Indentation," Diffusion in Solids and Liquids Iv, Cilt 283-286, 675-680, 2009.

4. R. Ivanov, "Two-Component Diffusive Steel Saturation," Materials and Manufacturing Processes, Cilt 24, No 7-8, 894-897, 2009.

5. Z. G. Su, X. Tian, J. An, Y. Lu, Y. L. Yang ve S. J. Sun, "Investigation on Boronizing of N80 Tube Steel," Isij International, Cilt 49, No 11, 17761783, 2009.

6. I. Campos, R. Rosas, U. Figueroa, C. V. Velazquez, A. Meneses, ve A. Guevara, "Measurement of Fracture Toughness in AISI 1018 Borided Steels by Vickers Indentation," Materials Science and Engineering aStructural Materials Properties Microstructure and Processing, Cilt 488, No 12, 562-568, 2008.

7. I. Campos-Silva, A. S. Balankin, A. H. Sierra, N. Lopez-Perrusquia, R. Escobar-Galindo ve D. Morales-Matamoros, "Characterization of rough interfaces obtained by boriding," Applied Surface Science, Cilt 255, No 5, 2596-2602, 2008.

8. Y. S. Nechaev ve A. Ochsner, "Essay on Techniques \& Physics of Some DiffusionControlled Processes in Materials: Relevance to Nanofabrication Applications," Diffusion in Materials - Dimat2008, Cilt 289-292, 679-686, 2009.

9. N. Lopez-Perrusquia, I. Campos-Silva, J. Martinez-Trinidad, A. Aviles, E. AlvarezCastaneda ve S. Juarez-Torres, "Evaluation of Brittle Layers Obtained by Boriding on AISI H13 Steels," Xvii International Materials Research Congress, Cilt 65, 47-52, 2009.

10. C. M. Li, B. L. Shen, G. J. Li ve C. Yang, "Effect of boronizing temperature and time on microstructure and abrasion wear resistance of Cr12Mn2V2 high chromium cast iron," Surface \& Coatings Technology, Cilt 202, No 24, 58825886, 2008.

11. K. Wisniewski, ve A. Pertek, "Influence of Laser Alloying with Amorphous Boron on Structure and Microhardness of $41 \mathrm{cr} 4, "$ Archives of Metallurgy and Materials, Cilt 54, No 1, 111114, 2009.

12. W. P. Ye, Z. L. Huang, Q. X. Zhang ve Q. Y. Zhang, "Microstructure and of mechanics microwave boriding," Journal of Wuhan University of Technology-Materials Science Edition, Cilt 23, No 4, 528-531, 2008. 
13. K. David, K. G. Anthymidis, P. Agrianidis, ve G. Petropoulos, "Characterization and tribological properties of boride coatings of steels in a fluidized bed reactor," Industrial Lubrication and Tribology, Cilt 60, No 1, 31-36, 2008.

14. M. K. H. Aliev ve A. Saboor, "Pulsed nanocrystalline plasma electrolytic boriding as a novel method for corrosion protection of CP-Ti (Part 1: Different frequency and duty cycle)," Bulletin of Materials Science, Cilt 30, No 6, 601-605, 2007.

15. V. I. Dybkov, W. Lengauer ve K. Barmak, "Formation of boride layers at the $\mathrm{Fe}-10 \% \mathrm{Cr}$ alloy-boron interface," Journal of Alloys and Compounds, Cilt 398, No 1-2, 113-122, 2005.

16. V. I. Dybkov, V. R. Sidorko, L. V. Goncharuk, V. G. Khoruzha ve A. V. Samelyuk, "Microstructure, Growth Kinetics, and Abrasive Wear Resistance of Boride Layers on $\mathrm{Fe}-30 \% \mathrm{Cr}$ Alloy," Powder Metallurgy and Metal Ceramics, Cilt 51, No 9-10, 518-530, 2013.

17. M. Castillo, M. Vite, L. H. Hernandez, G. Villa ve G. Urriolagoitia, "Wear and tear by fracture in boriding mechanical elements," Revista Mexicana De Fisica, Cilt 51, No 1, 11-15, 2005.

18. M. Darabara, G. D. Papadimitriou ve L. Bourithis, "Tribological evaluation of Fe-B-TiB2 metal matrix composites," Surface \& Coatings Technology, Cilt 202, No 2, 246-253, 2007.

19. C. Bindal ve A. H. Uçışık, "Characterization of boriding of $0.3 \% \mathrm{C}, 0.02 \% \mathrm{P}$ plain carbon steel," Vacuum, Cilt 82, No 1, 90-94, 2007.

20. V. I. Dybkov, "Growth of boride layers on the $13 \% \mathrm{Cr}$ steel surface in a mixture of amorphous boron and KBF4," Journal of Materials Science, Cilt 42, No 16, 6614-6627, 2007.

21. L. Y. Xu, X. C. Wu ve H. B. Wang, "Influence of surface nano-structured treatment on pack boriding of H13 steel," Journal of Materials Science \& Technology, Cilt 23, No 4, 525-528, 2007.

22. H. Çelikkan, M. K. Öztürk, H. Aydın ve M. L. Aksu, "Boriding titanium alloys at lower temperatures using electrochemical methods," Thin Solid Films, Cilt 515, No 13, 5348-5352, 2007.

23. K. Genel, I. Özbek ve C. Bindal, "Kinetics of boriding of AISI W1 steel," Materials Science and Engineering a-Structural Materials Properties Microstructure and Processing, Cilt 347, No 1-2, 311-314, 2003.

24. R., Chattopadhyay, Advanced Thermally Assisted Surface Engineering Processes, Kluwer Academic Publishers, Massachusetts, A.B.D. Cilt XV. 2004.

25. ASM Handbook, Alloy Phase Diagrams, ASM International, Cilt 3, A.B.D., 1992.

26. I. Campos, G. Ramirez, U. Figueroa ve C. V. Velazquez, "Paste boriding process: evaluation of boron mobility on borided steels," Surface Engineering, Cilt 23, No 3, 216-222, 2007.

27. M. Kulka ve A. Pertek, "The importance of carbon content beneath iron borides after boriding of chromium and nickel-based lowcarbon steel," Applied Surface Science, Cilt 214, No 1-4, 161-171, 2003. 
